\title{
Practical Research on the Moral Education in High School Aerobics Teaching
}

\author{
Jin Sha ${ }^{1}$, Yongjun Zhao ${ }^{2,}{ }^{*}$ \\ ${ }^{1}$ Beijing Hepingjie No.1 Middle School, Beijing, China \\ ${ }^{2}$ Basic Course Department, Beijing Institute of Fashion Technology, Beijing, China \\ *zfitness@163.com
}

\begin{abstract}
Integrating moral education into physical education is one of the effective ways for the country to foster the socialist successors with all-round development of moral, intellectual, physical and aesthetic grounding with a hard-working spirit, aerobics has the unique moral education value and educational significance of "fitness, heart-building and bodybuilding". Based on the discussion of characteristics of aerobics, value of moral education and characteristics of students' learning, This paper believes that by integrating moral education into teaching objectives, teaching contents, teaching evaluation and teaching rethink in the high school stage, the fundamental task of "strengthen moral education and cultivate people" in the physical education discipline can be effectively implemented.
\end{abstract}

Keywords: aerobics, moral education.

\section{Introduction}

Physical education discipline is an important part of the middle school curriculum, and it is also a course to train students to have a good physique and healthy living habits. With the promotion of quality education and the thorough implementation of new curriculum reform, integrating moral education into physical education has become one of the effective ways for the country to foster socialist successors with all-round development of moral, intellectual, physical and aesthetic grounding with a hard-working spirit. Therefore, in the aerobics education and teaching process of high school stage, the teachers not only help students improve their athletic ability and healthy behavior as the main purpose, but also pay attention to developing students' aggressiveness, integrity and self-discipline, and other good sports morality. More importantly, it is necessary to carry out the "strengthen moral education and cultivate people" and "fitness education" moral education concept into all links of aerobics classroom teaching, and cultivate students' ability and habits for lifelong healthy life.

\section{Teaching Characteristics of High School Aerobics Course}

\subsection{Characteristics of Aerobics}

Accompanied by music with strong rhythm, aerobics arranges the movements in gymnastics and dance according to the rhythm of music; make students continue to follow the music to complete the whole body movement within a period of time, it is a sport designed to promote health, enjoy the body and mind, and shape the body. Aerobics can exercise the heart and lung function and core strength of students, when students continue to complete their movements and maintain a high heart rate, their cardiopulmonary function, lower limb strength and core muscle group strength can be significantly improved. Moreover, a complete set of aerobics movement can exercise all parts of the body from head to foot, the flexibility exercise and basic posture training is conducive to form a straight and upright body posture; all kinds of wave turning and other movements are helpful to develop the tight waist and abdomen muscles; all kinds of kicking and hip movements contribute to lift the whole gravity; various chest-expanding and stretch exercises conduce to form a body-building shape with chest out and stretch shoulder. 


\subsection{Moral Education Value of Aerobics Course in High School}

Aerobics teaching has distinct times characteristics, which is not only an important method of high school physical education teaching, but also a teaching method combining strength with beauty, and it has a very important impact on the improvement of students' comprehensive quality. Digging deeply the value of moral education in the teaching process is the first step for high school physical education teachers to integrate moral education into the classroom. From classroom contents, aerobics teaching in high school is rich in contents and diverse in forms, teachers can flexibly adjust exercise intensity according to students' physical quality level, and encourage students to combine and arrange basic technical movements and formation transformations with small groups. The students' collective consciousness and creative ability can be cultivated and exerted to a large extent in the movement arrangement, and students' correct understanding for power beauty and physical beauty can be established. In organizational form, actively carrying out various types of aerobics clubs and interest groups on campus is another important way to integrate physical education into moral education, by organizing and participating in aerobics competitions, students can understand aerobics and historical and cultural background of important events, which fosters the sports culture literacy rooted in the students, it has a positive and beneficial impact on the formation of students' lifelong sports quality.

\subsection{Learning Characteristics of Aerobics Course in High School}

High school students are in the puberty; they have strong curiosity and thirst for knowledge, are eager to understand and touch beautiful things, and often encounter new situations and challenges. In addition, high school students have basically formed values for the world around them, and they have their own judgments and aesthetic views on things. Therefore, the aerobics course should pay attention to the cultivation of students' personal temperament, shape, interest and specialty, help students to correct the "concerned" bad physical problems in time, and encourage students to confidently demonstrate the combination of "strength" and "beauty". In particular, it is worth noting how minority students in the class can better participate in group activities. Therefore, it is necessary to give full play to the advantages of China's excellent ethnic traditional culture, encourage the group of minority students to choose folk songs with regional characteristics as musical accompaniment, and add national dance movements to the group works, so that the aerobics with the times significance and the excellent traditional art with the national wisdom produce positive link and contact, and promote cultural exchanges and national unity.

\section{Specific Practice of Integrating Moral Education into Aerobics Teaching of High School}

\subsection{Improve Students' Collective Consciousness and Sense of Responsibility through the Design of Teaching Goals Integrating into Moral Education}

The teaching goal points to the aim and task of teaching; it is the teaching result and standard that teachers and students expect to achieve in teaching activities. Therefore, the design of the teaching goals integrating moral education is an important practical way to carry out the teaching of aerobics education in senior high school. Different from the basic three-dimensional goals of knowledge skills, ability methods, emotional attitudes and values, the advanced three-dimensional goals of happy learning, well learning, and good use are more able to reflect the moral education concept of teachers' support students to master basic technology, develop own abilities, and internalize sports quality. Among them, the goal of happy learning is to cultivate students' positive sports attitudes and healthy sports behaviors, such as "arouse students' exercise interest under the accompaniment of music, and the physical training in aerobics is no longer boring through the exercise of pedals and elastic bands," the goal of good learning is to help students develop good sports ethics, such as "use self-learning teaching model, so that students develop collective consciousness and sense of responsibility in practice, and cultivate comprehensive ability and sports quality in the process of solving problems"; the goal to good use is to promote students' personalized learning and transform applications, such as 
"follow students' learning characteristics, encourage students to exert creativity and arrange aerobics products, so that students can be more willing to accept and have the determination to persist in training."

\subsection{Cultivate Students' Sports Cultural Quality by Organizing and Integrating the Teaching Contents of Moral Education}

Teaching contents are the scope and depth of imparting knowledge and skills in teaching activities in order to achieve educational goals. Therefore, the teaching contents which organize and integrate moral education are strong practical guarantees to realize the infiltration of "strengthen moral education and cultivate people" in aerobics education and teaching of high school stage. When learning aerobics, students need to do a lot of movement skills training and physical reserve training in order to show a beautiful physical state and healthy sports spirit. Compared with other disciplines, physical education discipline is more likely to reflect the real physical and psychological quality of students. Therefore, in the teaching and learning process of aerobics, through group display, collective participation and other forms, students are gradually cultivated to be aggressive, brave and hardworking, respect for referees and other excellent morality, encourage students to understand the gymnastics spirit and competitive sports rules behind aerobics, and effectively promote the improvement and internalization of students' sports culture quality based on moral grace.

\subsection{Affirm Students' Learning Ability and Creativity through the Implementation of Teaching Evaluation Integrated with Moral Education}

Teaching evaluation is to conduct comprehensive evaluation for efficiency of teaching and learning activities in teaching activities. The teaching evaluation which integrates moral education is the key practice form to help the aerobics teaching in senior high school to implement "fitness education". By actively guiding and supporting students to complete aerobics movement arrangement and music independently, teachers can not only provide students with imagination and creation space, but also integrate the cultural elements of different nationalities in the group, carry forward independent innovative spirit and realize plural sharing and cooperation. In addition, targeted teaching evaluation will have a positive impact on students' self-esteem and self-confidence. When the students are studying the technical movements seriously and assiduously, the teachers should give full affirmation and praise, the teachers can use the way of students' demonstration to stimulate the power of example, and further strengthen the students' internal learning motivation of sports.

\subsection{Improve Teachers' Own Teaching Ability through Teaching Rethink Integrating into Moral Education}

Teaching rethink is a comprehensive and deep summary of teachers' teaching activities and classroom teaching practice as the thinking object, and improves their classroom practice based on the results. Doing a good job in the teaching rethink of moral education is the "strengthen moral education and cultivate people" fundamental practical requirement for implementing the aerobics education and teaching in high school. "Teachers impart professional knowledge and resolve doubts", teachers as direct objects to interact with students, their every word and action, every move is the imitation object of students. Therefore, teachers must strictly demand their own moral cultivation, only have good sports ability, healthy behavior and sports morality can they become qualified teachers with high quality, professionalization and innovation in the new era, and then socialist successors with Chinese heritage can be trained.

\section{Conclusion}

Physical education is an important symbol of social development and human progress, and it is an important manifestation of comprehensive national power and social civilization. Aerobics as one of the most popular physical education courses in high school, and it should seize the "fitness, heartbuilding and bodybuilding" triune educational opportunity to make aerobics teaching become the 
focus and breakthrough for implementing comprehensive education of school physical education in the new era.

\section{References}

[1]. Shi Yuehong. Discussion on How to Infiltrate Humanistic Quality Education in College Aerobics Teaching[J]. Sport, 2016(19): 105-106.

[2]. Ma Ji. Aerobics Teaching in Moral Education Research[J]. Contemporary Sports Science, 2012, 2(30): 30-30.

[3]. Yang Zhiliang, Hao Xingchang. Psychology Dictionary[M]. Shanghai Dictionary Publishing House. 2016.

[4]. Chinese Encyclopedia Dictionary Editorial Board. Encyclopedia of China [M]. Huaxia Publishing House. 1999.

[5]. Lin Chongde. China Encyclopedia of Middle School Teaching. Education Volume [M]. Shenyang Press. 1990.

[6]. Duan Wenqiang. Teaching Rethink: The Only Way for the Growth of New Teachers[J]. Gansu Education, 2019 (11): 94. 